\title{
Engineering Service-Learning - Importance of Appropriate Collaboration with International Partners
}

\author{
Miriam R. Simon \\ PhD Student, Department of Education and Human Ecology \\ The Ohio State University \\ Columbus, $\mathrm{OH} 43210$ \\ simon.301@osu.edu \\ Gregory D. Bixler, PE \\ $\mathrm{PhD}$ Candidate, Department of Mechanical Engineering \\ The Ohio State University \\ Columbus, $\mathrm{OH} 43210$ \\ bixler.17@osu.edu \\ Bradley Doudican, PE \\ $\mathrm{PhD}$ Candidate, Department of Civil Engineering \\ The Ohio State University \\ Columbus, $\mathrm{OH} 43210$ \\ doudican.1@osu.edu \\ Roger Dzwonczyk, PE \\ Clinical Professor, Department of Anesthesiology \\ The Ohio State University \\ Columbus, $\mathrm{OH} 43210$ \\ dzwonczyk.1@osu.edu
}

\begin{abstract}
The service learning engineering/humanitarian engineering program at The Ohio State University has been in existence for seven years and has grown in both the number of participants and projects. On the international front, various partnerships have formed that create a framework for success for our participants as well as for the targeted communities that are served. The program, although focused mostly on engineering-related projects, also emphasizes the need for cultural awareness and constant communication with the in-country partners. The goal of the program is to raise awareness of the needs of citizens in developing nations and to collectively work together on sustainable solutions. This paper will describe the development of humanitarian engineering at The Ohio State University and chronicle partnership at two specific locations in Honduras.
\end{abstract}

Index Terms - service learning engineering, humanitarian engineering, collaboration, cultural awareness, appropriate technology, sustainable solutions.

\section{INTRODUCTION}

The Humanitarian Engineering (HE) service-learning program at The Ohio State University (OSU) began in 2005 as a collaboration between the student organization Engineers for Community Service (ECOS) and the College of Engineering. In an effort to increase awareness of global issues as well as to establish hands-on learning experiences for students, several faculty members created an engineering course that culminated in a week-long service-learning trip to Montaña de Luz (MdL), an orphanage in Honduras. Students developed 
projects in areas such as irrigation, gardening, water quality, computers, facility infrastructure, food production, energy conservation and alternative energy throughout the course and implemented their projects during the trip. The popularity and success of these collaborative projects at MdL sparked an interest in expanding the program. Following an assessment trip by faculty and students in the spring of 2010, the HE program established a partnership with World Gospel Mission (WGM), a mission organization in Choluteca. In 2011, students went to Choluteca to complete projects on a computer lab, an aquaponics system, and an assessment on model homes and wind generators in collaboration with WGM and Escuela Vocacional Estados Unidos de America (United States of America Technical School), a nonprofit vocational schools. Student involvement in the partnerships with MdL and WGM has grown since the program's inception (Figure 1).

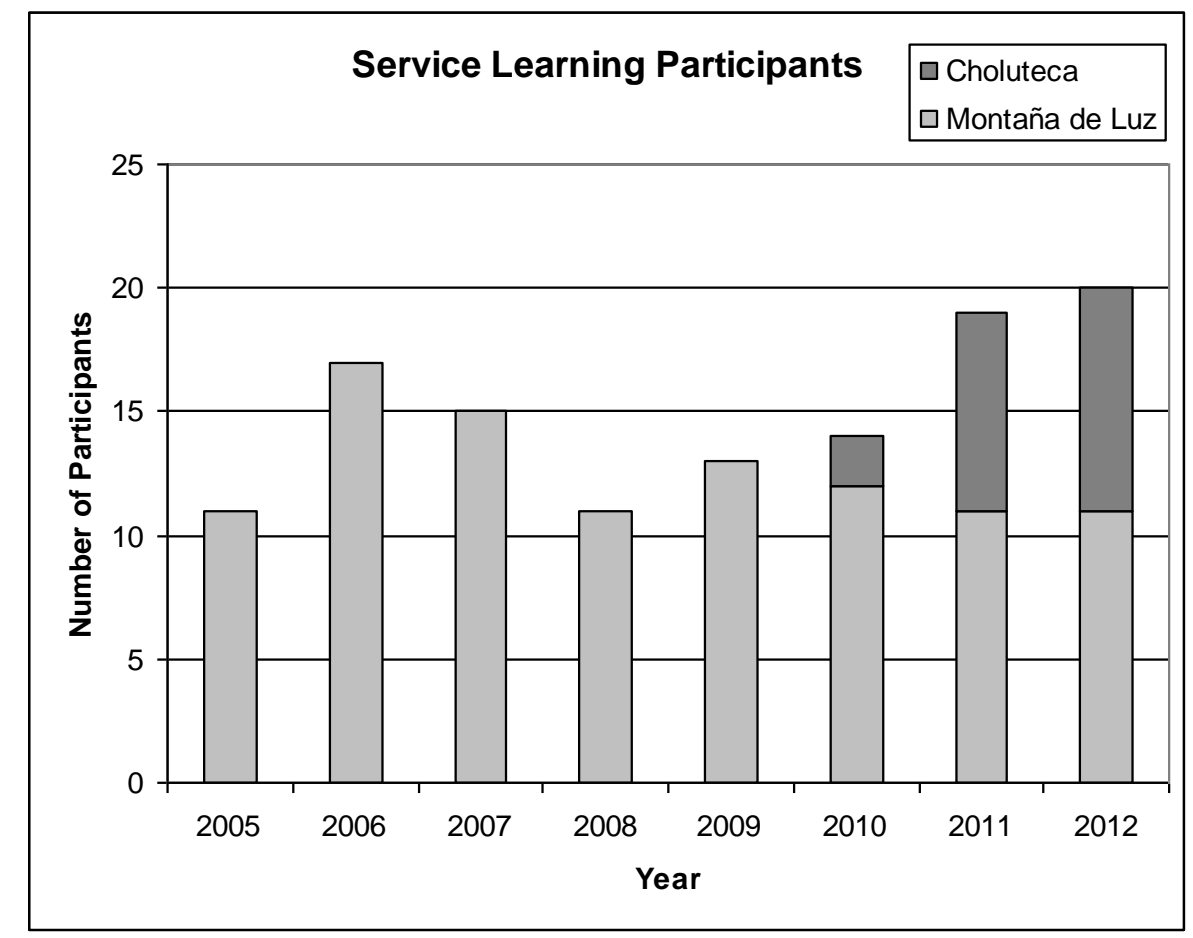

FIGURE 1

NUMBER OF SERVICE LEARNING PARTICIPANTS

In preparation for the week-long trips, students participate in a quarter-long course developing technologies that will benefit the local population in Honduras. The course raises awareness of global issues, sustainability, and proper communication. During the course, students interact with guest speakers from various disciplines. Students also spend time interacting with the Honduran partners in order to make sure projects are truly collaborative, a keystone for success. Students are responsible for determining timelines, budgets, materials, and additional documentation.

OSU's HE/service learning program is not a new concept on college campuses. Engineering Projects in Community Service (EPICS) at Purdue University is a program that prepares engineers to work with the community through various projects. Their website clearly states the need for university programs on service-learning by stating that "undergraduate students face a future in which they will need more than solid expertise in their discipline to succeed. They will be expected to work with people of many different 
backgrounds to identify and achieve goals. They need educational experiences that can help them broaden their skills."

Smith reiterates the point made by the National Survey of Student Engagement that "the frequency with which students participate in activities that represent effective educational practice is a meaningful proxy for collegiate quality and, therefore, by extension, quality of education."2 However, as Skokan states in her paper, there are five major challenges when undertaking a service-learning course. ${ }^{3}$ The following considerations should be taken into account by the university, the lead professors, and the students before committing to service-learning.

- The identification of a project

- Funding the project(s)

- Trip and project logistics

- Health and safety of participants.

- Building local trust and rapport.

One of the most important points made by Skokan is that although students and community members are the ones who collaboratively come up with solutions, the community must still have ownership of the project in order to guarantee sustainability. As Muñoz states in his paper, there have been many failed attempts and projects regarding $\mathrm{HE}$, many of these due to a lack of proper communication of the ultimate benefits for the partners, the time commitment needed to sustain the projects, and ultimately knowledge of cultural and political situations. ${ }^{4}$

\section{Engineers for Community Service}

The HE initiative at OSU originated largely as a result of the formation of the student organization ECOS. The organization promotes volunteerism and life-long professionalism via educational experiences in the application of engineering and technical skills for local and international community service projects. In conducting HE missions, the organization attempts to improve the lives of as many people as possible in the most economical and sustainable ways. The focus of ECOS is on how to engage the skills of engineers for community service, and in particular on education and design of sustainable, cost-effective, culturally appropriate technology to improve human conditions in the global community (www.ecos.osu.edu).

A goal of ECOS is to help bridge the global technological divide though education and specific technology service projects. Successful educational or technology projects typically involve forming partnerships with the community in order to: (i) address their highest priority needs; (ii) enlist local help on the project to understand and overcome cultural divides and ensure successful project completion; and (iii) establish local ownership to deal with the impact of a project. Such impact comes in many forms, including the impact of technology on the environment, public discourse, the economy, education, cultural attitudes and public health.

ECOS aids the OSU College of Engineering in meeting certain requirements of the Accreditation Board for Engineering and Technology (ABET), the accrediting agency for colleges of engineering, technology and computer science in the United States. In its function, ECOS addresses ABET's requirement for understanding ethical and professional responsibilities and contemporary issues, the global and societal impact of engineering solutions, sustainability and economics. In addition to its international work in Honduras, ECOS actively serves its local community by, for instance, teaching computer skills to the elderly, operating a call-in tutoring program for high school and middle school students, and building 
wheelchair ramps for handicapped residents in the city. Membership in the organization currently numbers over 200 students.

\section{Core Group}

Building and maintaining partnerships both in the United States and abroad are paramount for the success of any HE service-learning program. Trusted relationships with in-country stakeholders are necessary when investigating how to develop appropriate technology and to ensure long-term success. Furthermore, there needs to be mutual benefits for both the university and in-country stakeholders for the relationship to be sustainable. Lastly, the relationship needs continuous maintenance through regular communication. Such a relationship was developed with both MdL and our Choluteca partners.

When searching for out-of-country stakeholders, the mutual benefits of partnering with MdL were clear due to the close proximity of their headquarters in Columbus. For the last seven years, service-learning teams have worked alongside the MdL staff to provide engineering support in the form of capital improvements as well as product design efforts. In 2009, a new partnership with WGM and the directors of the vocational school was developed in addition to MdL to offer more advanced engineering work for upperclassmen. Additionally, certain WGM personnel are OSU alumni, have worked with OSU nursing students for several years, and were interested in hosting the engineering service-learning team.

Upon returning to OSU after the 2011 spring break service-learning trip, there was a significant amount of momentum, excitement, and energy to continue working on HE projects. In the past, the service-learning teams have informally suspended activity for several months after the spring break trip. Typically in late summer and early fall, a small core group of faculty and students would start to discuss the next service learning opportunity. Up until this period of time, little to no communication was made between the Honduran stakeholders and the OSU program staff or students. Often the relationship suffered and this arrangement did not allow the excited and motivated students to continue HE work after the trip, which was important in keeping the momentum going. Frequently there is follow up work to conduct after the trip but no motivation or formal means to continue.

The staff at OSU recognized the opportunity for improvement in fostering a yearlong relationship with the MdL and WGM personnel. Thus, starting immediately after the last service-learning trip, a core group of motivated staff and students started a weekly "brown bag" lunch meeting for anyone interested in "continuing the conversation". The brown bag meetings help to keep the conversation alive with both the OSU students and staff as well as with the Honduran stakeholders. This was meant to promote student engagement through weekly meetings where everyone would assemble to discuss relevant topics. Through periodic Skype calls, emails, and visits the group has continued providing support, gaining feedback from previous projects, and learning about new opportunities with our international partners. The brown bag meetings also serve as a platform to talk about other HE opportunities being conducted by the staff and students outside of the OSU service-learning program. This helps to improve the service-learning program by continually building on the HE knowledge base through discussion of case studies and lessons learned.

Student support is critical and many of the Honduras trip team members have taken leadership roles. One objective is to continue the projects throughout the year and use the prerequisite service-learning class as a foundation for teaching students about appropriate and sustainable technology. Another is to expand the program and collaborate with other entities around OSU that work in the field of humanitarian aid, providing the platform for potential interdisciplinary approach for future work. Initially the brown bags attracted engineering service-learning participants, but now it attracts participants from the OSU schools of business, sociology, and architecture. Each contained outreach focused service-learning programs, but did 
not collaborate with the College of Engineering for projects. The service-learning projects often contain overlap between majors and require interdisciplinary teams, which are critical for success.

Part of the continuing OSU HE work has been to support the participating students and staff in the presentation of current HE work at conferences. Delegations have traveled and presented at the National Outreach and Scholarship Conference (Michigan State University), OSU Denman Undergraduate Research forum, and the Institute for Electrical and Electronic Engineers (IEEE) Global Humanitarian Technology Conference (Seattle, WA). These all proved to be invaluable experiences in showing OSU's work as well as learning from other programs and leaders in the field. In fact, posters from these conferences have won awards and attracted positive attention for both OSU and the individual authors.

Growth and development of a formal HE program at OSU is gaining momentum, especially from the supportive staff of the Engineering Education Innovation Center (EEIC). A common obstacle to HE programmatic success in higher education is integrating HE into required coursework. Often students and staff support the concept, but there lacks incentive for the tenured faculty to engage. The momentum is gaining and OSU is starting to offer more HE themed courses through the EEIC, including the first HE seminar course in Fall 2011. One of the popular guest presentations was a Skype call with the founder of the Free Wheelchair Mission and a hands-on activity that involved the assembly of the organization's wheelchairs (www.freewheelchairmission.org).

Another result emerging from the brown bag luncheons is discussion about starting a new formal HE scholars program as well as a HE senior design capstone course. The new HE scholars program is being developed to offer an alternative program for advanced students to study HE. This special program consists of a scholarship and a living/learning arrangement where students take classes together and also live in the same dormitories. Previous scholars programs have proven to be quite popular and successful for fostering engineering excitement and retention, both important College-level metrics of success. The HE senior design capstone project is also gaining traction. One group from the recent engineering service-learning trip was able to incorporate a HE project for their course, but this required special petitioning. Additional effort is underway to develop curriculum that educates students in appropriate technology design concepts. This type of initiative is gaining momentum due to the effort of EEIC staff and others who are motivated to offer such programs.

\section{Case Study 1 - Montaña de LuZ}

Montaña de Luz is an orphanage for children affected by HIV/AIDS located in a rural region of Honduras 50 miles east of the capital Tegucigalpa, near the villages of El Paraiso and Nueva Esperanza. These communities were established for Hondurans displaced by Hurricane Mitch, which struck the country with devastating effect in 1998. MdL began as a place of rescue and a hospice for children living with HIV/AIDS. In 2001, it welcomed its first child. Today the hospice role has been eliminated due to the introduction of antiretroviral drugs in Honduras, and MdL has grown to be a home for 35 children of all ages, complete with clean living quarters, purified water, proper medical care, loving staff, educational support and a nurturing family atmosphere. MdL strives to be a self-sustaining environment for children and families both infected and affected by HIV/AIDS, providing employment, foster family care, improved educational opportunities and access to health and medical services. Its mission addresses the needs of its own children and families, assisting them with the resources needed to live as fully as possible and to allow them to contribute to their own culture. OSU has been involved with MdL since 2005 when two faculty advisors of ECOS visited the facility and assessed the engineering opportunities at the orphanage. 


\section{Electric Energy Usage}

Over the past six years, OSU students have made improvements in the electric power system at the orphanage. The students prepared a detailed line drawing of the electric energy distribution system. They corrected many hazardous and unsafe conditions in the wiring. In an effort to reduce the electric energy usage, the students performed an energy audit of the facility and made numerous recommendations that would decrease electric energy usage, including, for instance, switching to more efficient lighting sources (compact fluorescent light bulbs and T8 fluorescent tubes and ballasts). In the process, the students took the opportunity to meet with the Honduran national electric company in order to learn the country's initiatives in electric energy conservation. A current ongoing project at MdL is investigating possible renewable electric energy alternatives to grid power. This project may reduce the cost of electric energy in the long term and be a backup energy source for the unreliable grid energy.

\section{Computer Lab/Internet Access}

The students set up a computer lab for the children in what was once a morgue, but now, is unneeded because of the improved medical treatment received by the children. Over the years, the students installed computers that they refurbished and transported from OSU to the orphanage as seen in Figure 2. They installed Spanish-language operating systems and educational software that was either purchased through fundraising or donated by software companies. The students rewired the computer lab with power, lighting, fans and air conditioning. The students designed and installed a wireless network throughout the facility, giving both the children and staff access to the internet for the first time. Each year the students maintain and upgrade the system with improved technology and educational software and provide continuing education during their service-learning trips to the facility.

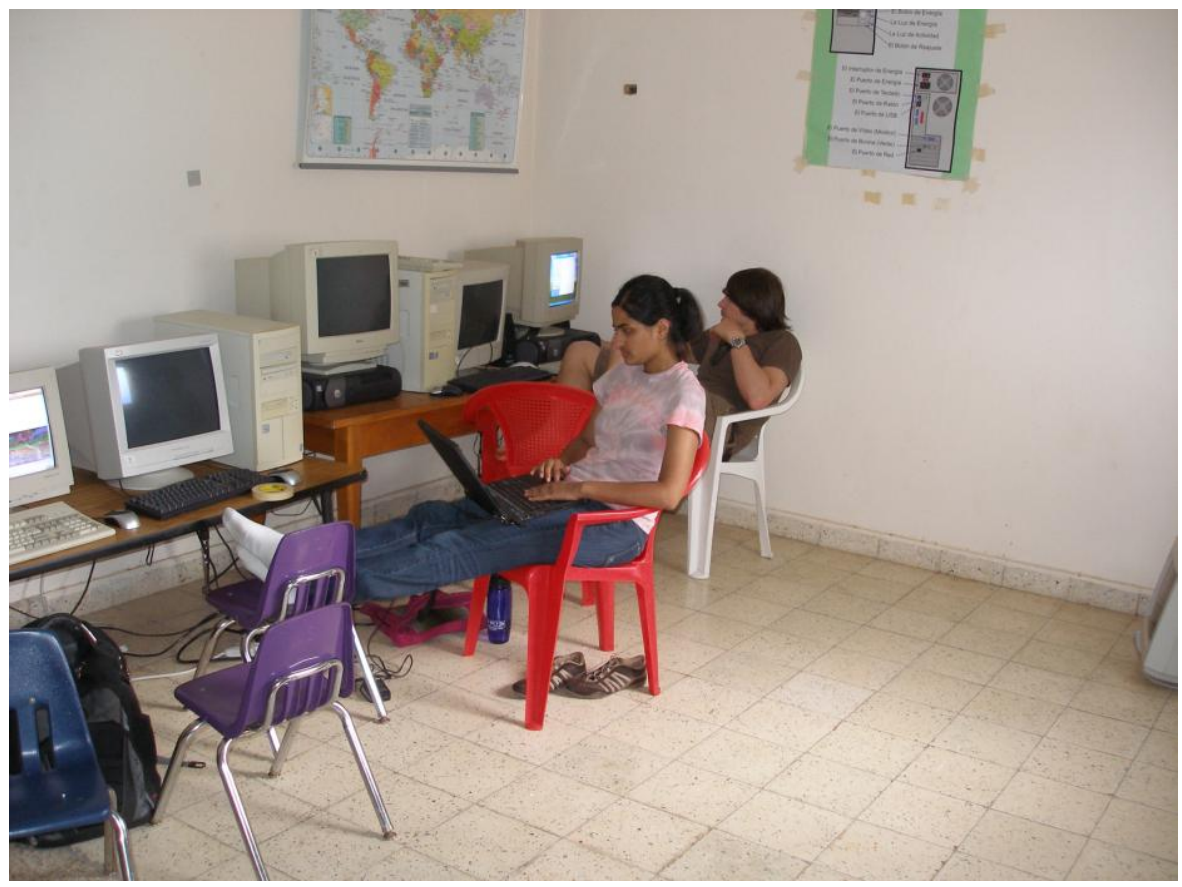

FIGURE 2

COMPUTER LAB AT MONTAÑa DE LUZ 


\section{Agriculture}

At MdL, an electric pump is used to deliver water from a well over 200 -feet deep. That water is delivered to several elevated tanks on the campus from where it is distributed throughout the compound. Given the variable and relatively high cost of electricity, efficient use of water directly impacts the operational budgets. In light of this necessity, the students designed and installed an easy-to-operate drip irrigation system for the orphanage's garden and orchard. The new irrigation system is simple, requires very little maintenance, and saves a significant amount of water over the conventional sprinkler system used in the past. Additionally, a series of shade nets were constructed over the garden area to protect the plants from scorching in the equatorial sun. (see Figure 3). The combination of efficiently-delivered water and protected growth areas has permitted the orphanage to provide supplemental nutritional resources for the children at minimal cost.

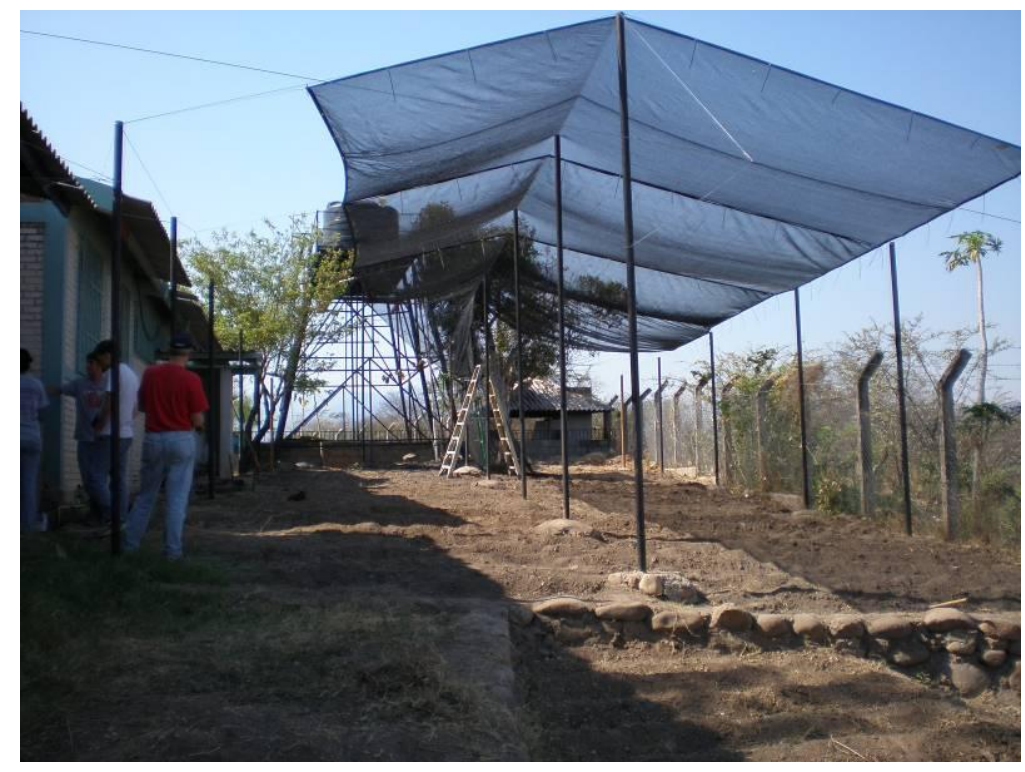

FIGURE 3

SHADE NETTING FOR GARDENS

\section{Water Quality}

The students analyzed the water quality of the well water used at the orphanage and made repairs and modifications in the water distribution system to help improve water quality. The students installed water filters at the sinks in the kitchen that help improve the quality of the water used for drinking and cooking. In addition, these students analyzed the water for the adjacent community as well, and established a relationship with the village's water council to help them improve water quality for the entire village. Currently, discussions and preliminary investigations are underway to separate the water distribution system on the campus to deliver untreated water for non-potable uses, such as toilets, wash basins, and agriculture, and to deliver treated water for potable uses only. This will significantly reduce the cost of treatment.

\section{Passive Cooling}

In 2010, the students investigated and implemented several passive cooling technologies that improved the working and living conditions of the staff and children of the orphanage. One methodology involved growing leaved vines to shield the buildings from the sun's direct rays. The most effective method was to coat the roof of the building with reflective paint. The methods passively lowered the inside temperature of 
the buildings during the day, were inexpensive to implement, and represented sustainable solutions. Students quantitatively measured the impact of their designs through structured temperature surveys while onsite.

\section{Tilapia Farming}

Across the developing world, a common source of malnutrition is the lack of protein in the diets of many. Fish farming has been demonstrated around the world as an effective mechanism to provide not only supplemental protein, but also to provide a potential source of income for the farmer. Tilapia is a hardy breed of fish that are commonly grown on fish farms at production scales ranging from tens of fish in backyard basins to tens of thousands in large lagoons. A previous effort by others had been undertaken at MdL to implement tilapia farming, but lack of planning and sustainable design prohibited the continued operation. In 2010, OSU students undertook the project to educate themselves and assess the opportunities for tilapia farming at MdL. This included a trip to visit tilapia experts at Zamorano (Figure 4A), a worldrenowned agricultural school located near the MdL campus. The following year students from OSU extended and implemented the designs, culminating in the exciting release of over 500 tilapia fry (Figure 4B), obtained from Zamorano, into the renovated pond structures. Six months later, the first harvest was collected.
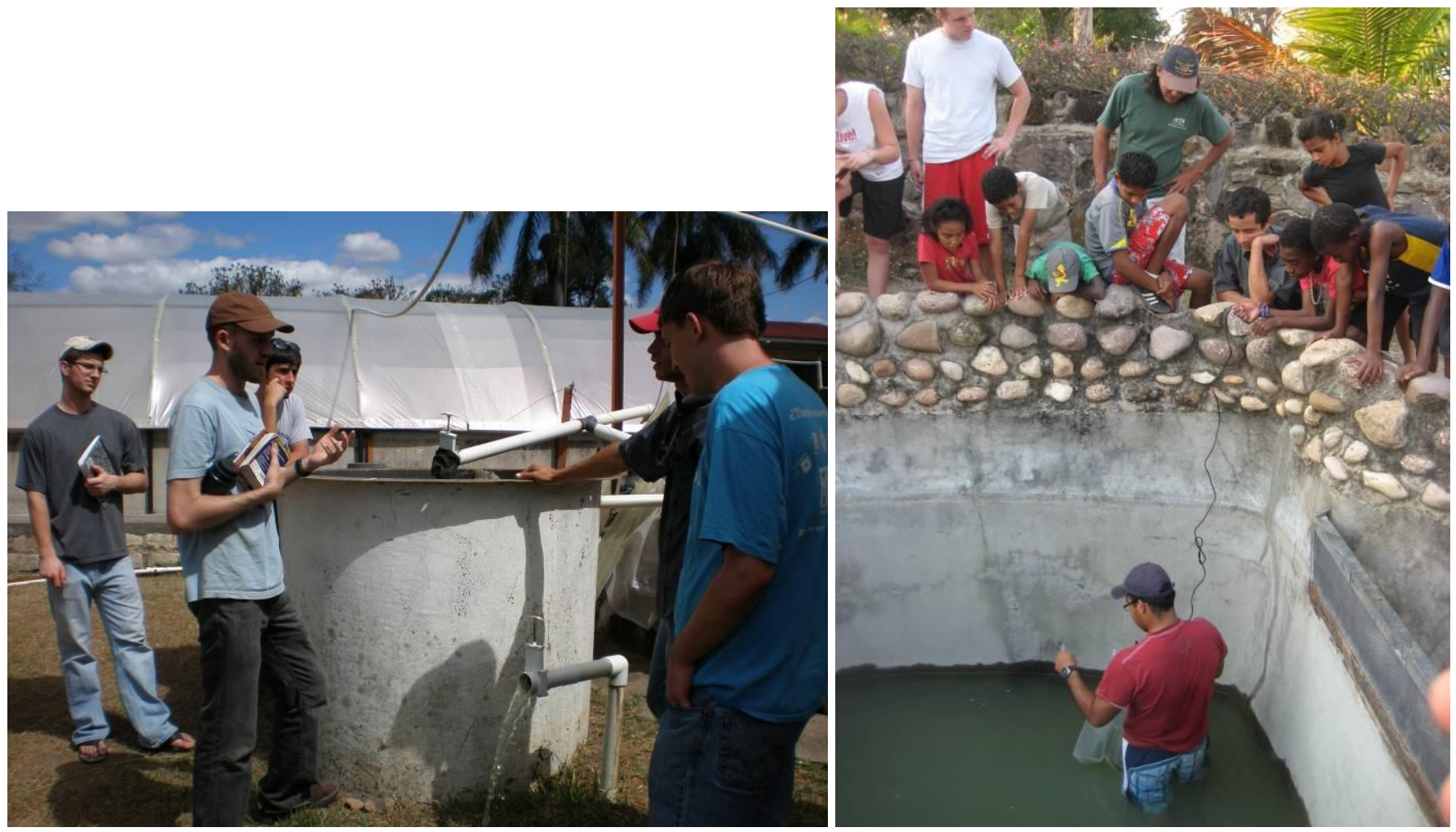

FIGURE 4

(A) LEARNING ABOUT TILAPIA FARMING AT ZAMARANO

(B) TILAPIA RELEASE AT MDL

\section{Asset Mapping}

Over several years of involvement at MdL, both OSU and MdL leaders recognized two operational shortcomings: 1) technical knowledge of the campus infrastructure and operations resided only in the minds 
of one or two key maintenance personnel; and 2) re-education in the practices of facility operations through staff transitions was often unclear or incomplete. An "Asset Mapping" program was initiated in 2010 and 2011 to attempt to redress these concerns. A physical survey of the facility, including architectural as well as infrastructure layout was completed and drafted (see Figure 5). Then, an additional survey of staff was conducted to better understand operations, collect copies of important documents, and identify opportunities for strategic improvement and growth. All of this was compiled into an interactive, hypertext-linked interactive electronic map.

Outcomes of this project extended beyond the initial goals as all parties discovered that the process of mapping resulted in the understanding of strategic, physical, social, and cultural opportunities in partnership for MdL, as well as a tool for strategic growth. Through this map, future projects and their solutions are no longer isolated from the greater context of their physical, social, and cultural environment in which they are implemented.

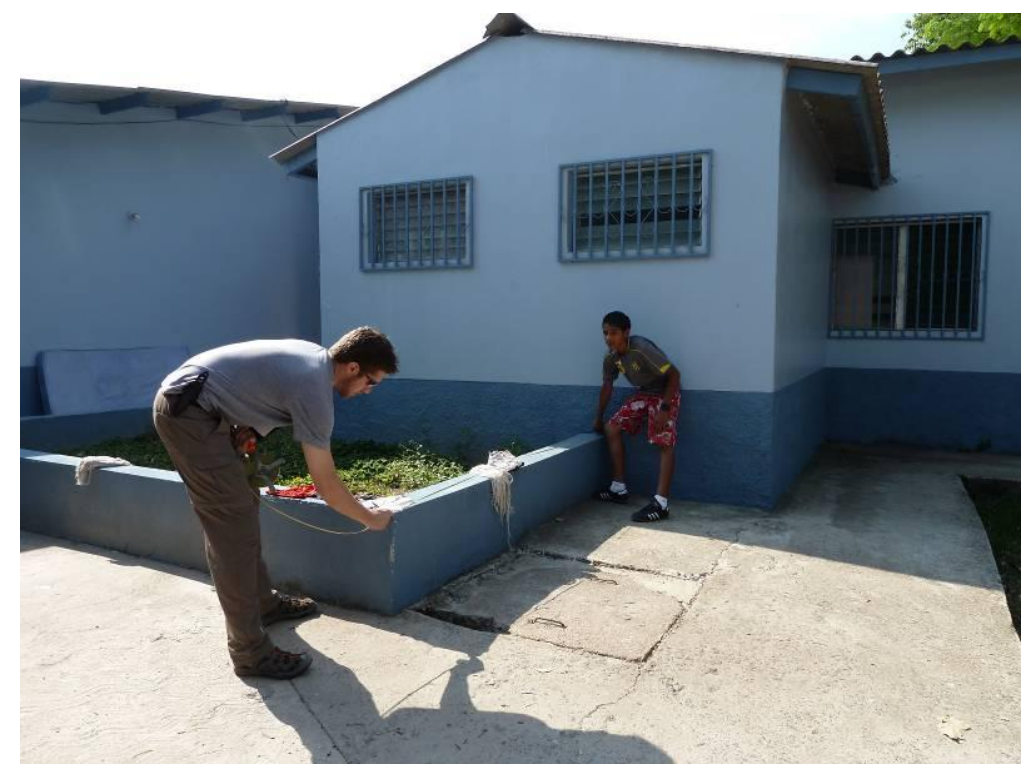

FIGURE 5

ASSET MAPPING WITH LOCAL HELP

Case Study 2 - Choluteca

\section{Choluteca, Honduras}

The city of Choluteca is located in the southern part of the country, bordering two Honduran departments on the north and west, Nicaragua on the east, and the Pacific Ocean on the south. With a population of approximately 100,000 people, Choluteca is considered to be one of the largest and most productive cities in Honduras. Industries include agriculture, fishing, metal refinement, and salt. ${ }^{5}$ Choluteca was heavily damaged by Hurricane Mitch in 1998 and therefore much of the city has needed to be rebuilt since that time.

\section{Escuela Tecnica Estados Unidos de America (United States of America Technical School)}

Located on the outskirts of the city of Choluteca is the vocational school Estados Unidos de America. This school is dedicated to teaching automotive mechanics, refrigeration, air conditioning systems, sewing, and 
computer literacy. Although the school provides students with basic facilities for learning, the school lacks electricity in some of the buildings as well as running water on a daily basis. There are a handful of potential projects at the school that would not only benefit OSU students but also the vocational school students as well as the community. Many of these projects have been brought to the attention of the university by the school's director. Figure 6 depicts one of the buildings at the vocational school.

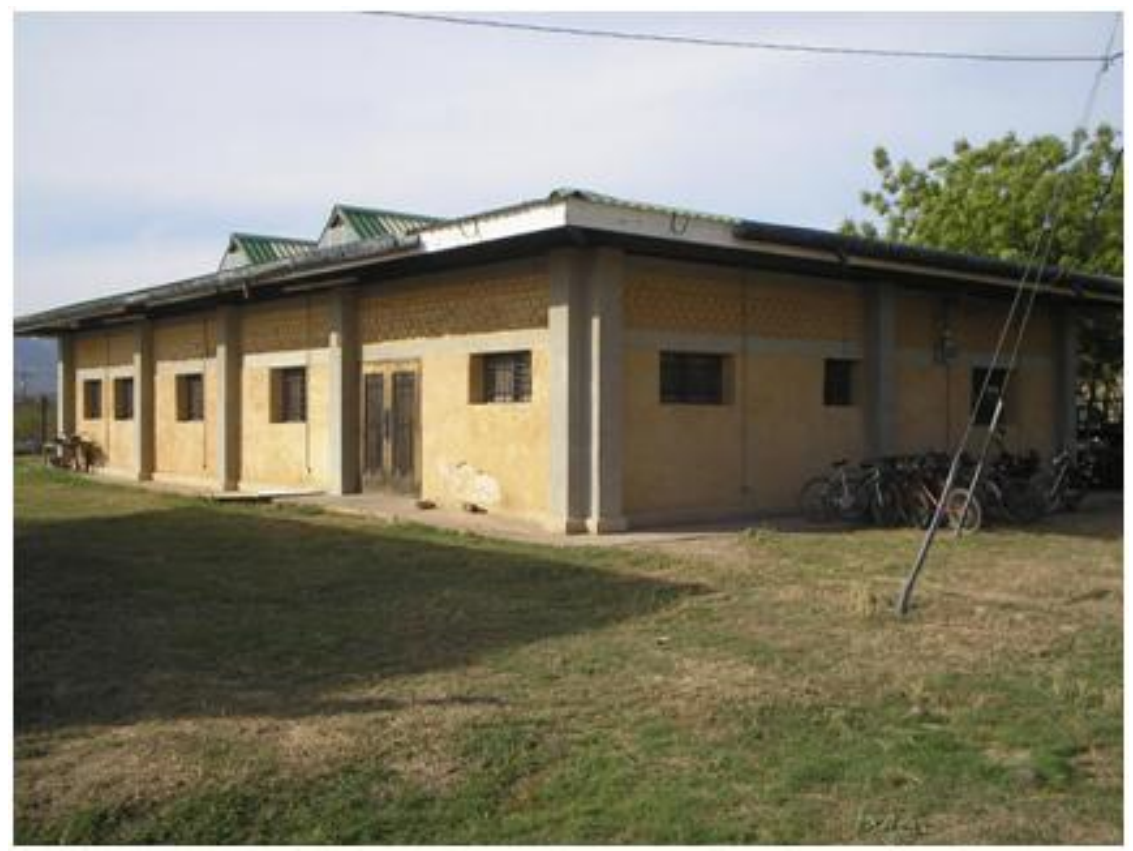

Figure 6

ONE OF THE BUILDINGS AT THE VOCATIONAL SCHOOL

The school's director is an agronomist by education and his wife is a nurse who operates a clinic. They are both missionaries and have lived in Honduras for 25 years. They have become trusted members of the community and are involved in many local activities. They have been excellent points of contact in Honduras and constant communication with them has proven to be essential for the projects that have begun there in the past few years.

Two of the main projects completed during the 2010 trip included the installation of an aquaponics system as well as the maintenance and installation of software at the computer lab. A smaller project consisted of the assessment of local homes in order to propose a design for a model home. One of the authors conducted extensive research on the possibility of installing small-scale wind generators at the school as part of her master's thesis work.

\section{Aquaponics}

Aquaponics is a system comprised of two or more basins, one used for fish and one used for plants. The water from the fish tank containing effluents is pumped to the plant tank. The plants consume the nutrients from the water, clean it, and filter it back to the fish tank. The cyclical nature of an aquaponics system is ideal for those who want to produce both a protein source and vegetables in a small amount of space. Although the system is scalable, the proposal from the in-country partners to the OSU students was to build 
a fully functioning aquaponics model that would be ideal for a family of five. The main concern was to find a system that would power the water pump independently of grid power, as power delivery is not reliable in that area of Honduras. Due to abundant sunshine in southern Honduras, solar panels were selected as the power source. They also served as inspiration for the vocational school students to learn about alternative energy. The completed aquaponics system is shown in Figure 7.

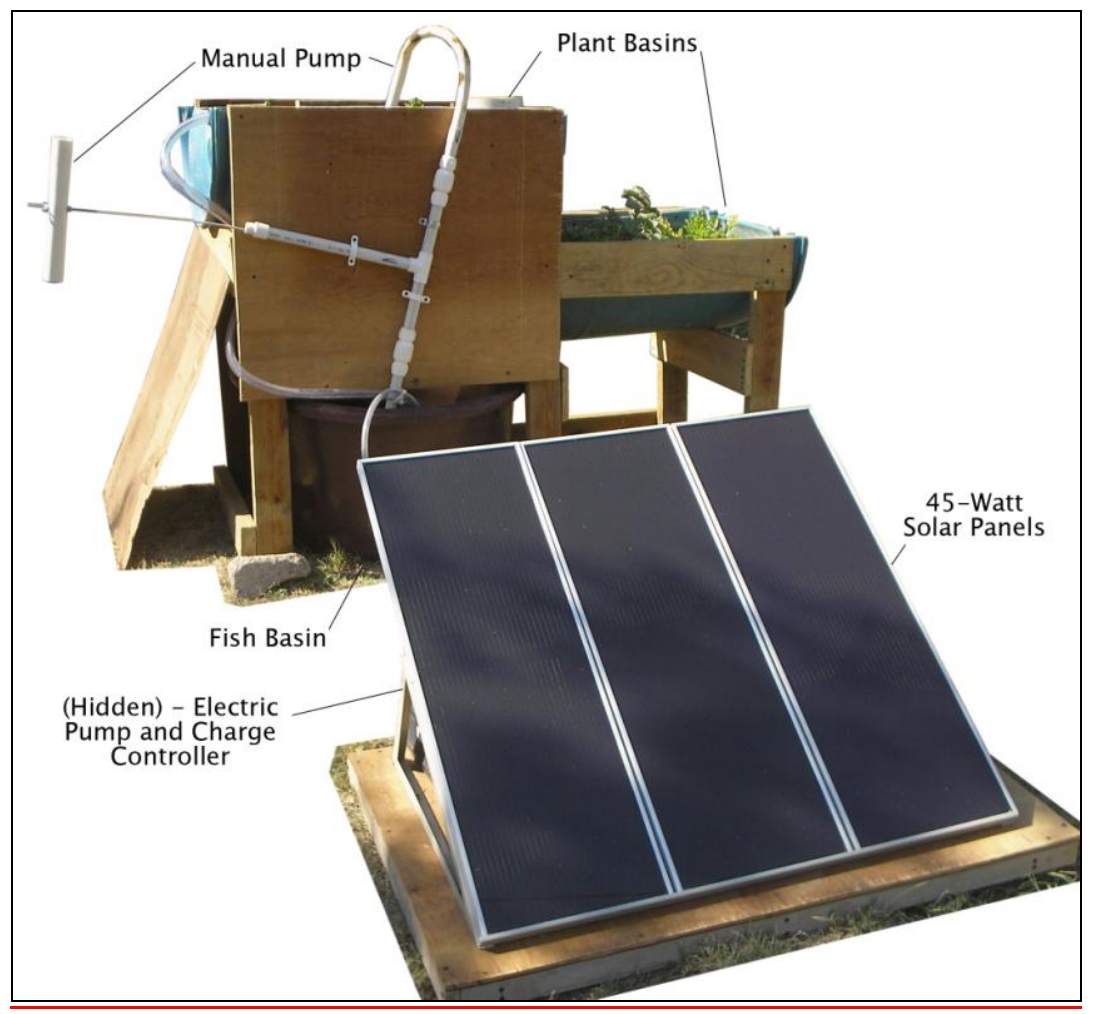

FIGURE 7

THE AQUAPONICS SETUP AT THE VOCATIONAL SCHOOL

OSU students were given a budget of 400 USD and were able to complete the project for about \$320 USD. Students used scrap wood and barrels that were available at the vocational school, as well as a deep-cycle marine battery that was no longer in use. Solar panels, pumps and a timer were purchased in the United States, but are also available in Honduras for purchase. Nine months since implementation, the aquaponics system is functioning; it is being taken care of by the school's director and one of the school's maintenance workers. Increased interest in the aquaponics system was shown by the students at the school.

Constant communication between the OSU service-learning team and the in-country partners proved to be essential for project completion. A timeline of the in-country activities proved to the students that they would have to work efficiently and effectively and in some cases design-on-the-go. Communication occurred through e-mail, Skype teleconferences, and even a visit by the school's director to OSU. Even after the project was completed, members of the service learning team were communicating with the in-country partners to ensure an enduring partnership. Students will be traveling to Honduras once again in March of 2012. 


\section{CONCLUSIONS AND FUTURE WORK}

Successful international HE partnerships rely on constant communication and collaboration with in-country partners. These efforts not only promote future projects but allow partners to maintain ownership of the current ones. College-level students who participate in service-learning projects graduate with an awareness of different cultures, ethics, sustainability, and the need for constant collaboration and feedback in order to ensure project success, keeping in mind the requirements stipulated by ABET. Engineering faculty and staff at OSU have worked hard at maintaining relationships with partners for many years in order to facilitate communication efforts, encourage sustainability and success of long-term service-learning projects.

One of the goals for the program is to extend the week-long trip to a month-long trip in order to allow for more in-depth projects and more hands-on time for students. The new direction will drastically change the scope of the projects as students will be able to work on larger-scale issues. Year-long seminars are also being considered to maintain program momentum. Increasing interest in the engineering service-learning program at OSU is a clear marker that students are becoming more aware of global issues and want to use their skills to help those in need.

\section{ACKNOWLEDGEMENTS}

The authors would like to thank Dr. John Merrill, Dr. Robert J. Gustafson, and Dr. Howard Greene, as well as the Engineering Education Innovation Center and the Ohio State University College of Engineering for their support. Thank you to our Honduran partners at Montaña de Luz and Choluteca.

\section{REFERENCES}

1 "Overview : EPICS." College of Engineering, Purdue University. Web. 5 Dec. 2011. $<$ https://engineering.purdue.edu/EPICS/About>.

2 Smith, Karl A., Sheri D. Sheppard, David W. Johnson, and Roger T. Johnson. "Pedagogies of Engagement: Classroom-Based Practices." Journal of Engineering Education 94.1 (2005): 87-101.

3 Skokan, Catherine, and David Munoz. Humanitarian Engineering Program - Challenges in the Execution of Remote Projects. Proc. of International Conference on Engineering Education, Coimbra, Portugal.

${ }^{4}$ Muñoz, David R., and Catherine K. Skokan. "Humanitarian Engineering Programme: Conceptual Challenges." World Transactions on Engineering and Technology Education 6.2 (2007): 253-255.

${ }^{5}$ http://www.choluteca.honduras.com 